\title{
Functional Haplotype Frequencies of the Interleukin-1B Promoter in the Korean Population
}

\author{
Kyung-A Lee* \\ Department of Laboratory Medicine, Yonsei University \\ College of Medicine, Seoul 120-749, Korea
}

\begin{abstract}
Single nucleotide polymorphisms (SNPs) in the promoter region of the $\angle L-1 B$ (interleukin-1) gene have been implicated in a variety of diseases that have an inflammatory component. However, there has been significant heterogeneity among study results, especially between Caucasian and Asian populations. Recently, it has been reported that SNPs in the $I L-1 B$ gene affect transcription, according to haplotype context, and genetic association studies may be more informative if functional SNP haplotypes of population are analyzed. Therefore, we estimated the distribution of $I L-1 B$ promoter haplotypes in 433 Koreans using the three major functional $/ L-1 B$ promoter SNPs $(/ L-1 B-1464,-511$, and -31) and compared the results with those in Caucasians. The difference in IL-1B promoter haplotype frequency between Korean and Caucasian populations was statistically significant. The potentially more inflammatory haplotypes had higher frequencies in Koreans when compared with Caucasians. These Korean haplotype data will be useful for future association studies between $I L-1 B$ SNPs and disease risk.
\end{abstract}

Keywords: Interleukin-1B; polymorphism; haplotype; Korean

SNPs in the promoter region of $/ L-1 B$ gene have been implicated in a variety of diseases that have an inflammatory component, including cardiovascular disease, gastric cancer, Alzheimer disease, and periodontal disease (lacoviello et al., 2005; Camargo et al., 2006; Griffin et al., 2000; Kornman et al., 1997). The IL-1B gene is highly polymorphic, and several SNPs have been frequently associated with several diseases (lacoviello et al., 2005; Francis et al, 1999; El-Omar et al., 2000). However, there has been significant heterogeneity among study results, especially between Caucasian and Asian populations (Camargo et al., 2006;

${ }^{*}$ Corresponding author: E-mail KAL1119@yuhs.ac

Tel +82-2-2019-3531, Fax +82-2-3462-9483

Accepted 11 March 2008
Lee et al., 2004; Yang et al., 2004; Zeng et al., 2003; Chang et al., 2005; Ma et al., 2003; Hodge et al., 2001).

Recently, Chen et al (Chen et al., 2006) reported that SNPs in the $/ L-1 B$ gene affect transcription according to haplotype context, and genetic association studies may be more informative if functional SNP haplotypes are analyzed, rather than individual functional SNPs. Further, they showed that the functional haplotypes differ by ethnic population. These findings underlie the relevance of population haplotypes in the design of genetic studies (Chen et al., 2006). In view of these findings, we estimated the distribution of $I L-1 B$ promoter haplotypes in 433 Koreans using three major functional $/ L-1 B$ promoter SNPs ( $/ L-1 B-1464,-511$, and -31$)$ and compared the results with those in Caucasian and African populations. Although the $/ L-1 B-3737$ polymorphism also had allele-specific differences in nuclear protein binding, no differences in promoter activity were observed with different alleles of this SNP on a background of the other SNP sets that showed higher promoter activity (Chen et al., 2006). Because it has been suggested that the functional significance of $/ L-1 B-3737$ might depend on a broader haplotype, we used the three SNPs for haplotype analysis. Haplotypes were reconstructed by PHASE version 2.1, using previously produced genotype data (Lee et al., 2004).

Of the possible eight haplotypes, three common ones accounted for $\geq 98 \%$ of the estimated haplotypes in the Korean population. Table 1 shows the haplotype frequency estimation in each population. The potentially more inflammatory $/ L-1 B-511 \mathrm{~T} /-31 \mathrm{C}$ haplotype represented $53.5 \%$ of the Korean haplotypes, compared with $33.7 \%$ of the Caucasian haplotypes. So far, in many previous association studies, the individual SNP approach, most frequently using $/ L-1 B-511$ and $I L-1 B-31$, has been adopted. To our knowledge, we reported first that the $I L-1 B-1464$ polymorphism has allele-specific differences in nuclear protein binding and is associated with a clinical disease (Lee et al., 2004). The biological implication of this polymorphism was supported by in vivo studies by Chen et al. that showed that the $I L-1 B-1464$ polymorphism has substantial allele-specific effects when both $I L-1 B-511$ and $I L-1 B-31$ were alleles $\mathrm{T}$ and $\mathrm{C}$, respectively (Chen et al., 2006). The more informative haplotype 1 (GTC), containing the $/ L-1 B-1464$ polymorphism, which shows the highest transcriptional activity, represents $9.3 \%$ and $6.0 \%$ of Korean and Caucasian haplotypes, respectively, whereas haplotype 
Table 1. Common haplotype frequencies of IL1B promoter

\begin{tabular}{|c|c|c|c|c|c|c|c|}
\hline \multirow{3}{*}{$\begin{array}{c}\text { Haplotype } \\
\text { IL1B-1464/-511/-31 } \\
\text { (Transcriptional activity*) }\end{array}$} & \multicolumn{7}{|c|}{ Haplotype frequency (\%) } \\
\hline & \multicolumn{4}{|c|}{ Korean $^{\dagger}$} & \multirow{2}{*}{$\begin{array}{c}\mathrm{CHB}^{\mathrm{N}}+\mathrm{JPT}^{\dagger} \\
\quad(\mathrm{n}=89)\end{array}$} & \multirow{2}{*}{$\begin{array}{l}\text { Caucasian }^{*} \\
(\mathrm{n}=900)\end{array}$} & \multirow{2}{*}{$\begin{array}{l}\text { African } \\
(\mathrm{n}=227)\end{array}$} \\
\hline & $\begin{array}{l}\text { Case } \\
(n=433)\end{array}$ & $\begin{array}{l}\text { Gastric cancer } \\
\quad(n=331)\end{array}$ & $\begin{array}{l}\text { Diffuse } \\
(\mathrm{n}=188)\end{array}$ & $\begin{array}{c}\text { Intestinal } \\
(n=133)\end{array}$ & & & \\
\hline GTC (High) & 9.3 & 10.2 & 8.4 & 11.9 & 10.1 & 6.0 & 46.1 \\
\hline CTC (Intermediate) & 44.0 & 44.2 & 49.7 & 37.0 & 35.4 & 27.7 & 10.6 \\
\hline GCT (Low) & 44.8 & 44.2 & 40.2 & 50.0 & 53.9 & 64.8 & 42.0 \\
\hline Total & 98.1 & 98.6 & 98.3 & 98.9 & 99.4 & 98.5 & 98.7 \\
\hline
\end{tabular}

*Data are from Chen et al., 2006.

†Japanese and Chinese results are from international Hapmap data.

${ }^{\dagger}$ Haplotypes were reconstructed using previously produced genotype data from Lee, et al., 2004.

3 (GCT), with the lowest activity, had a higher frequency in Caucasians $(64.8 \%)$ when compared with Koreans $(44.2 \%)$ (Table 1). The difference in $/ L-1 B$ promoter haplotype frequency between the Korean and Caucasian populations was statistically significant $\left(\chi^{2}=20.6\right.$, $p=0.000)$, and the allele frequencies of the $/ L-1 B-1464$ polymorphism (rs\#1143623) were also significantly different between the two populations ( $/ L-1 B-1464 \mathrm{G}$ allele frequencies for Korean and Hapmap European $=0.548$ and 0.672 , respectively) $\left(\chi^{2}=6.38, p=0.01\right)$.

It has been suggested that genes that are involved in immune function may be under selective pressure in direct interaction with the environment (Sawyer et al., 2004; Kim et al., 2005). The genes that influence a phenotypic variation between populations are expected to show high Fst values. Compared with the Fst value for the Caucasian-vs-Asian comparison, the Fst values for the African-vs-Asian or -Caucasian comparisons were remarkably high (Fig. 1).

Previously, we reported that the $I L-1 B-1464$ polymorphism contributes to the development of intestinal-type gastric cancer among Koreans (Lee et al., 2004). As a curious finding in our report, the editor pointed out that carriers of $I L-1 B-1464 \mathrm{G}$ tend to have a decreased risk of diffuse-type of gastric cancer, which is the opposite of intestinal-type gastric cancer, although both intestinal and diffuse types of gastric cancer are related to Helicobacter pylori-induced gastritis (Furuta et al., 2004). Our results showed that most $I L-1 B-1464 \mathrm{C}$ alleles are linked to the $/ L-1 B-511 \mathrm{~T} /-31 \mathrm{C}$ haplotype (Table 1$)$. Considering the level of promoter activity of haplotype 2 (CTC), we cannot exclude the possible association between this haplotype and the risk of diffuse-type gastric cancer, especially depending on interactions with other regulatory factors (Lee et al., 2007). Association studies that use individual SNPs appear to be insufficient, and the understanding of functional haplotype structure of populations could provide

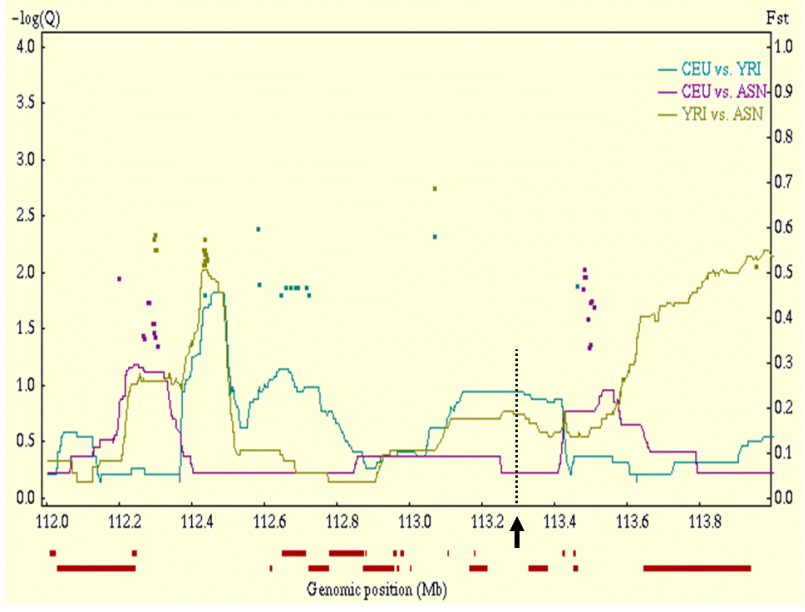

Fig. 1. Population pairwise Fst values for the $I L 1 B$ promoter region (113.3 Mb, data from Voight et al., 2004.

potential explanations for $/ L-1 B$-related controversies and ethnic-specific associations. Therefore, we believe that these Korean haplotype data will be useful for future association studies between $I L-1 B$ SNPs and disease risk.

\section{Acknowledgements}

This work was supported by the Korean HapMap Project from the Korean Ministry Science \& Technology and the Korean National Institute of Health.

\section{References}

lacoviello, L., Di Castelnuovo, A., Gattone, M., Pezzini, A., Assanelli, D., Lorenzet, R., Del Zotto, E., Colombo, M., Napoleone, E., Amore, C., D'Orazio, A., Padovani, A., de Gaetano, G., Giannuzzi, P., and Donati, M.B. (2005). Polymorphisms of the interleukin-1beta gene affect the 
risk of myocardial infarction and ischemic stroke at young age and the response of mononuclear cells to stimulation in vitro. Arterioscler Thromb Vasc Biol. 25, 222-227.

Camargo, M.C., Mera, R., Correa, P., Peek, R.M.Jr., Fontham, E.T., Goodman, K.J., Piazuelo, M.B., Sicinschi, L., Zabaleta, J., and Schneider, B.G. (2006). Interleukin1 beta and interleukin-1 receptor antagonist gene polymorphisms and gastric cancer: a meta-analysis. Cancer Epidemiol Biomarkers Prev. 15, 1674-1678.

Griffin, W.S., Nicoll, J.A., Grimaldi, L.M., Sheng, J.G., and Mrak, R.E. (2000). The pervasiveness of interleukin-1 in alzheimer pathogenesis: a role for specific polymorphisms in disease risk. Exp Gerontol. 35, 481-487.

Kornman, K.S., Crane, A., Wang, H.Y., di Giovine, F.S., Newman, M.G., Pirk, F.W., Wilson, T.G.Jr., Higginbottom, F.L., and Duff, G.W. (1997). The interleukin-1 genotype as a severity factor in adult periodontal disease. $J$ Clin Periodontol. 24, 72-77.

Francis, S.E., Camp, N.J., Dewberry, R.M., Gunn, J., Syrris, P., Carter, N.D., Jeffery, S., Kaski, J.C., Cumberland, D.C., Duff, G.W., and Crossman, D.C. (1999). Interleukin1 receptor antagonist gene polymorphism and coronary artery disease. Circulation. 99, 861-866.

El-Omar, E.M., Carrington, M., Chow, W.H., McColl, K.E., Bream, J.H., Young, H.A., Herrera, J., Lissowska, J., Yuan, C.C., Rothman, N., Lanyon, G., Martin, M., Fraumeni, J.F.Jr., and Rabkin, C.S. (2000). Interleukin-1 polymorphisms associated with increased risk of gastric cancer. Nature 404, 398-402.

Lee, K.A., Ki, C.S., Kim, H.J., Sohn, K.M., Kim, J.W., Kang, W.K., Rhee, J.C., Song, S.Y., and Sohn, T.S. (2004). Novel interleukin 1beta polymorphism increased the risk of gastric cancer in a Korean population. J Gastroenterol. 39(5), 429-433.

Yang, J., Hu, Z., Xu, Y., Shen, J., Niu, J., Hu, X., Guo, J., Wei, Q., Wang, $X$., and Shen, H. (2004). Interleukin-1B gene promoter variants are associated with an increased risk of gastric cancer in a Chinese population. Cancer Lett. 215, 191-198.

Zeng, Z.R., Hu, P.J., Hu, S., Pang, R.P., Chen, M.H., Ng,
M., and Sung, J.J. (2003). Association of interleukin 1B gene polymorphism and gastric cancers in high and low prevalence regions in China. Gut. 52, 1684-1689.

Chang, Y.W., Jang, J.Y., Kim, N.H., Lee, J.W., Lee, H.J., Jung, W.W., Dong, S.H., Kim, H.J., Kim, B.H., Lee, J.I., and Chang, R. (2005). Interleukin-1B polymorphisms and gastric mucosal levels of IL-1beta cytokine in Korean patients with gastric cancer. Int J Cancer. 114, 465-471.

Ma, S.L., Tang, N.L., Lam, L.C., and Chiu, H.F. (2003). Lack of association of the interleukin-1beta gene polymorphism with Alzheimer's disease in a Chinese population. Dement Geriatr Cogn Disord. 16, 265-268.

Hodge, P.J., Riggio, M.P., and Kinane, D.F. (2001). Failure to detect an association with IL1 genotypes in European Caucasians with generalised early onset periodontitis. $J$ Clin Periodontol. 28, 430-436.

Chen, H., Wilkins, L.M., Aziz, N., Cannings, C., Wyllie, D.H., Bingle, C., Rogus, J., Beck, J.D., Offenbacher, S., Cork, M.J., Rafie-Kolpin, M., Hsieh, C.M., Kornman, K.S., and Duff, G.W. (2006). Single nucleotide polymorphisms in the human interleukin-1B gene affect transcription according to haplotype context. Hum Mol Genet. 15, 519-529.

Sawyer, S.L., Emerman, M., and Malik, H.S. (2004). Ancient adaptive evolution of the primate antiviral DNA-editing enzyme APOBEC3G. PLOS Biol. 2, E275.

Kim, I.C., Chi, S.W., Kim, D.W., Choi, S.H., Chae, S.H., and Park, H.S. (2005). Comparative Genomics Study of Interferon-alpha Receptor-1 in Humans and Chimpanzees. Genomics \& Inform. 3, 142-148.

Furuta T, Shirai N, and Sugimoto M. (2004). Controversy in polymorphisms of interleukin-1beta in gastric cancer risks. J Gastroenterol. 39, 501-503.

Voight, B.F., Kudaravalli, S., Wen, X., and Pritchard, J.K (2006). A map of recent positive selection in the human genome. PLOS Biol. 4, e72.

Lee, K.A., Park, J.H., Sohn, T.S., Kim, S., Rhee, J.C., and Kim, J.W. (2007). Interaction of polymorphisms in the interleukin 1B-31 and general transcription factor 2A1 genes on the susceptibility to gastric cancer. Cytokine 38, 96-100. 